\title{
Faktor Sosial Ekonomi yang Mempengaruhi Produksi Usahatani Sayuran Sawi di Kelompok Tani Mitra Timor
}

\author{
Adelina Maria Usboko ${ }^{\mathrm{a}}$, dan Yosefina Marice Fallo ${ }^{\mathrm{b}}$ \\ ${ }^{a}$ Fakultas Pertanian, Universitas Timor, Kefamenanu, TTU - NTT, Indonesia. \\ ${ }^{b}$ Fakultas Pertanian, Universitas Timor, Kefamenanu, TTU - NTT, Indonesia.
}

\section{Article Info}

Article history:

Received 18 Mei 2016

\section{Keywords:}

Usahatani Sawi

Mitra Timor
Received in revised form 20 Juni 2016

Accepted 13 Juli 2016

Faktor Sosial Ekonomi

\begin{abstract}
Abstrak
Penelitian ini bertujuan untuk mengetahui gambaran usahatani sayuran sawi dan untuk mengetahui faktor sosial ekonomi yang mempengaruhi produksi usahatani sayuran sawi pada Kelompok Tani Mitra Timor di Kelurahan Benpasi, Kecamatan Kota Kefamenanu, yang dilaksanakan di Kelompok tani Mitra Timor Kelurahan Benpasi Kecamatan Kota Kefamenanu Kabupaten Timor Tengah Utara pada bulan Desember 2015 - bulan Maret 2016, dengan metode penetuan sampelnya adalah metode sensus yakni keseluruh anggota kelompok tani Mitra Timor di Kelurahan Benpasi sebanyak 20 orang dijadikan sebagai responden. Berdasarkan hasil penelitian menunjukkan bahwa gambaran usahatani sayuran sawi terdiri dari pengolahan lahan, persemaian, pemeliharaan terdiri dari penyiraman dan penyingan, panen, dan pasca panen. Berdasarkan uji F, secara bersama-sama luas lahan, bibit, pupuk kandang, curahan tenaga kerja, umur, pendidikan, dan jumlah tangungan keluarga berpengaruh nyata terhadap produksi sawi. Sedangkan berdasarkan uji t, secara parsial variabel luas lahan, bibit, pupuk kandang, dan jumlah tangungan keluarga berpengaruh nyata terhadap produksi sawi, sedangan variabel curahan tenaga kerja, umur, dan pendidikan, tidak berpengaruh nyata terhadap produksi sawi. (02016 dipublikasikan oleh Agrimor.
\end{abstract}

\section{Pendahuluan}

Sektor pertanian di Indonesia memegang peranan penting dari keseluruhan jenis perekonomian nasional. Hal ini terjadi karena Indonesia mempunya struktur sistem perekonomian agraris, dimana sebagian besar penduduknya bekerja di sektor pertanian. Salah satu sub sektor pertanian yang tidak kalah pentingnya dalam memenuhi kebutuhan dan meningkatkan pendapatan masyarakat yaitu sektor tanaman pangan dan hortikultura, diantaranya tanaman sayur-sayuran seperti sawi.

Sayuran sawi merupakan komoditi yang berprospek cerah, karena dibutuhkan sehari-hari dan permintaannya cenderung terus meningkat sebagaimana jenis tanaman hortikultura lainnya, kebanyakan tanaman sayuran sawi mempunyai nilai komersial yang cukup tinggi. Kenyataan ini dapa dipahami sebab sayuran senantiasa dikonsumsi setiap saat. Sawi (Brassica chinensis L.) merupakan salah satu jenis sayur yang digemari oleh masyaraka Indonesia. Konsumennya mulai dari golongan masyarakat kelas bawah hingga golongan masyarakat kelas atas. Di Indonesia sendiri banyak sekali jenis masakan atau penganan yang menggunakan daun sawi, baik sebagai bahan pokok maupun sebagai bahan pelengkapnya. Hal tersebut menunjukkan bahwa dari aspek sosial, masyarakat sudah menerima kehadiran sawi untuk konsumsi sehari-hari.

Di Kabupaten Timor Tengah Utara (TTU), Kecamatan Kota Kefamenanu, komoditi hortikultura khususnya sayur-sayuran mempunyai potensi dan peluang yang cukup besar mengingat kondisi dari agroklimat yang sangat mendukung. Salah satu komoditi sayuran yang banyak diusahakan oleh petani di Kelurahan Benpasi adalah sawi putih yang telah memberikan kontribusi yang cukup besa dalam meningkatkan tingkat perekonomian para petani. Nubatonis (2016) melaporkan bahwa usahatani sawi yang dilakukan di salah satu desa di Kabupaten TTU yakni desa Humusu Oekolo secara ekonomi menguntungkan sehingga layak dilanjutkan.

Keberhasilan usahatani dipengaruhi oleh faktor produksi (modal, tanah, tenaga kerja, dan manajemen). Modal diperlukan untuk pengadaan sarana produksi (bibit, pupuk, pestisida dan peralatan), biaya pemeliharaan tanaman, biaya penyimpanan, pemasaran dan pengangkutan. Petani cenderung mengalam hambatan dalam mengembangkan hasil usahataninya dengan menambah luas lahan maupun pengadaan sarana produksi (Darmawaty, 2005).

Faktor sosial ekonomi seperti umur, tingkat pendidikan petani, lamanya berusahatani, jumlah tanggungan keluarga, luas usahatani, bibit dan pestisida di kalangan setiap petani berbeda. Hal ini berkaitan dengan jumlah total pendapatan petani dan keluarganya sebagai upaya untuk meningkatkan kesejahteraan petani dan keluarganya melalui peningkatan produksi.

Dengan demikian perlu dilakukan penelitian secara langsung terhadap petan sawi untuk melihat pengaruh faktor sosial ekonomi (umur petani, tingka pendidikan petani, lamanya berusahatani, jumlah tanggungan keluarga, luas usahatani, bibit, dan pupuk) terhadap produksi usahatani sawi di kelompok tan Mitra Timor Kelurahan Benpasi Kecamatan Kota Kefamenanu Kabupaten TTU. Tujuan dari penelitian ini adalah untuk mengetahui gambaran usahatani sayuran sawi serta mengetahui faktor sosial ekonomi yang mempengaruhi produksi usaha tani sayuran sawi pada Kelompok Tani Mitra Timor di Kelurahan Benpasi, Kecamatan Kota Kefamenanu.

\section{Metode}

Penelitian dilaksanakan di Kelompok tani Mitra Timor Kelurahan Benpas Kecamatan Kota Kefamenanu Kabupaten Timor Tengah Utara pada bulan Desember 2015 - bulan Maret 2016, dengan metode penentuan sampelnya adalah metode sensus yakni keseluruhan anggota kelompok tani Mitra Timor di Kelurahan Benpasi sebanyak 20 orang dijadikan sebagai responden.

Untuk menjawab tujuan pertama menggunakan analisis deskriptif, sedangkan untuk menjawab tujuan kedua menggunakan analisis regresi linear berganda. Menurut Sudjana, (1992), regresi berganda menggambarkan hubungan antara 2 variabel. Variabel dependen $(\mathrm{Y})$ hanya satu variabel independen $(\mathrm{X})$ lebih dari satu. Persamaan regresi berganda dalam penelitian ini dapat ditulis sebagai berikut:

$$
\mathrm{Y}=\beta \mathrm{o}+\beta_{1} \mathrm{x}_{1}+\beta_{2} \mathrm{x}_{2}+\beta_{3} \mathrm{x}_{3}+\beta_{4} \mathrm{x}_{4}+\beta_{5} \mathrm{x}_{5}+\beta_{6} \mathrm{x}_{6}+\beta_{7} \mathrm{x}_{7}+\beta_{8 \mathrm{x} 8}+\beta_{9 \mathrm{x} 9+} \beta_{10} \mathrm{x}_{10+} \mathrm{e}
$$

Keterangan:

Y : produksi sayuran sawi (ikat)

Bo : intersep

B1- $\beta 6$ : Koefisien regresi dan variabel bebas

$\mathrm{X}_{1} \quad$ : Luas lahan (are)

$\mathrm{X}_{3} \quad$ : Pupuk kandang $(\mathrm{kg})$

$\mathrm{X}_{4} \quad$ : Curahan tenaga kerja (HKO)

$\mathrm{X}_{5} \quad$ : Umur (tahun)

$\mathrm{X}_{6} \quad$ : Tingkat pendidikan formal (tahun)

$\mathrm{X}_{7} \quad$ : Jumlah tanggungan keluarga (orang)

Data primer yang diperoleh dari hasil wawancara dengan responden diolah dengan menggunakan bantuan software SPSS version 16.0. fungsi produksi yan diperoleh menggambarkan hubungan antara faktor produksi yang diduga berpengaruh $(\mathrm{X})$ terhadap produksi usahatani sayuran sawi (Y).

\section{Hasil dan Pembahasan}

3.1 Gambaran Usahatani Sayuran Sawi di Kelompok Tani Timor

\section{- Pengolahan Lahan}

Berdasarkan hasil penelitian menunjukkan bahwa sistem pengolahan lahan dilakukan dengan cara tanah dibalik menggunakan linggis. Setelah tanah dibalik langsung pembuatan bedeng dengan ukuran panjang 10 meter, 12 meter, dan 15 meter, lebar 1 meter, tinggi bedeng $20 \mathrm{~cm}$, jarak antar bedeng $20 \mathrm{~cm}$ sedangkan jarak antar blok $50 \mathrm{~cm}$, setelah itu bedengan diberi pupuk kandang sebagai pupuk sadar. Bedengan siap ditanami sayur manis.

○ Penyemaian

Persemaian yang dilakukan pada kelompok tani Mitra Timor yakni lahan yang sudah disediakan untuk persemaian di sirami air terlebih dahulu kemudian ditaburi benih sayur manis dan ditutupi lagi dengan tanah sehingga taburan bibit sawi tertutup dan tidak dimakan burung atau ayam. Persemaian dilakukan pada sore hari selama 14 hari setiap hari pagi dan sore selalu disiram.

- Penanaman

Penanaman dilakukan setelah bibit sayur manis mempunyai daun 3-4 helai daun, sebelum menanam bedengan harus di sirami air, baru ditanami dengan jarak tanam $\pm 5 \mathrm{~cm} \times 5 \mathrm{~cm}$ atau $1 / 2$ jengkal.

○ Pemupukan

Pupuk yang digunakan adalah pupuk kandang sebelum tanam dengan takaran 25kg/bedeng. Berdasarkan hasil wawancara ditemukan bahwa pemupukan hanya pupuk dasar selanjutnya tidak ada lagi pemupukan.

- Pemeliharaan

Pemeliharaan meliputi penyiraman dan penyiangan. Penyiraman dilakukan setia hari selama 21 hari yakni pagi dan sore. Penyiangan biasanya dilakukan 2 hingga 4 kali selama masa penanaman sawi, disesuaikan dengan kondis keberadaan gulma pada bedeng penanaman. Biasanya penyiangan dilakukan 1 dan 2 minggu setelah penanaman. Apabila perlu dilakukan penggemburan bersama dengan penyiangan.

- Panen dan pasca panen.

Petani melakukan umur panen, setelah sayur sawi berumur 21 hari, saat panen petani terlebih dahulu melihat warnanya, bentuk, dan ukurannya. Sayu manis dicabut bersama akarnya kemudian disuci dengan air, lalu dipotong akarnya baru diikat sesuai kebutuhan atau harga yang sudah ditentukan.

\subsection{Faktor Sosial Ekonomi}

\section{a. Koefisien Determinan $\left(\mathbf{R}^{2}\right)$}

Dari hasil pendugaan model ditunjukkan juga bahwa nilai koefisien determinasi $\left(\mathrm{R}^{2}\right)$ di dapat sebesar 0,997 dengan nilai koefisien determinasi terkoreksi (R2-adjusted) sebesar 99,5\%. Nilai koefisien determinasi $\left(\mathrm{R}^{2}\right.$
$\mathrm{X}_{2} \quad$ : Bibit (gram) 
tersebut berarti bahwa sebesar 99,7 \% dari variasi produksi dapat dijelaskan secara bersama-sama oleh faktor umur, tingkat pendidikan, pengalaman usahatani, jumlah tanggungan keluarga, luas lahan, benih, dan pupuk kandang sedangkan sebesar $0,3 \%$ lagi dipengaruhi oleh faktor- faktor lain di luar model.

Tabel 1. Koefisien determinan $\left(\mathrm{R}^{2}\right)$ usahatani sayuran sawi pada kelompok tani Mitra Timor tahun 2016

\begin{tabular}{cccc}
\hline $\begin{array}{c}\text { Sumber } \\
\text { Keragaman }\end{array}$ & $\mathrm{R}$ & R Square & $\begin{array}{c}\text { Adjusted R } \\
\text { Square }\end{array}$ \\
\hline 1 & 0,998 & 0,997 & 0,995 \\
\hline
\end{tabular}

\section{b. Hasil Analisis Simultan}

Hasil uji F atau uji ANOVA menghasilkan F-hitung sebesar 160,47 > nilai F-tabel 2,28 atau nilai p-value $0,000<\alpha=0,1$. Hal ini menunjukkan bahwa model regresi tersebut dapat digunakan untuk memprediksi produksi sawi ( $\hat{Y} 1)$. Artinya variabel bebas luas lahan $\left(\mathrm{X}_{1}\right)$, bibit $\left(\mathrm{X}_{2}\right)$, pupuk kandang $\left(\mathrm{X}_{3}\right)$, curahan tenaga kerja $\left(\mathrm{X}_{4}\right)$, umur $\left(\mathrm{X}_{5}\right)$, pendidikan $\left(\mathrm{X}_{6}\right)$, dan jumlah tanggungan keluarga $\left(\mathrm{X}_{7}\right)$ berpengaruh nyata terhadap produksi sawi ( $\left.\hat{\mathrm{Y}} 1\right)$. Maka dapat disimpulkan bahwa $\mathrm{H} 1$ diterima dan Ho ditolak. Hasil analisis regresi yang berpengaruh secara bersama-sama terhadap produksi sayuran sawi dapat dilihat pada Tabel 2 .

Tabel 2. Hasil Analisis Simultan (Secara Bersama-sama) Luas Lahan $\left(\mathrm{X}_{1}\right)$, Bibit $\left(\mathrm{X}_{2}\right)$, Pupuk Kandang $\left(\mathrm{X}_{3}\right)$, Curahan Tenaga Kerja $\left(\mathrm{X}_{4}\right)$, Umur $\left(\mathrm{X}_{5}\right)$ Pendidikan $\left(\mathrm{X}_{6}\right)$, Jumlah Tanggungan Keluarga $\left(\mathrm{X}_{7}\right)$ Berpengaruh Terhadap Produksi Sayuran Sawi

\begin{tabular}{|c|c|c|c|c|c|}
\hline Sumber keragaman & $\begin{array}{l}\text { Jumlah } \\
\text { kuadrat }\end{array}$ df & $\begin{array}{c}\text { Rata-rata } \\
\text { Kuadrat }\end{array}$ & F hitung & Sig. & F tabel \\
\hline 1 Regresi & $5051903,89 \quad 7$ & 721700,58 & 511,96 & 0.000 & 2,28 \\
\hline Nilai Sisa & 16916,1012 & 1409,67 & & & \\
\hline Total & 5068820,0019 & & & & \\
\hline
\end{tabular}

Sumber: data primer (diolah) 2016

Berdasarkan Tabel 2. menunjukkan bahwa dengan tingkat kepercayaan $90 \%$ dengan $\alpha=10 \%$, luas lahan $\left(\mathrm{X}_{1}\right)$, bibit $\left(\mathrm{X}_{2}\right)$, pupuk kandang $\left(\mathrm{X}_{3}\right)$, curahan tenaga kerja $\left(\mathrm{X}_{4}\right)$, umur $\left(\mathrm{X}_{5}\right)$, pendidikan $\left(\mathrm{X}_{6}\right)$, dan jumlah tanggungan keluarga $\left(\mathrm{X}_{7}\right)$ secara bersama-sama berpengaruh sangat nyata terhadap produksi sayuran sawi.

\section{c. Hasil Analisis Parsial}

Hasil analisis pengaruh parsial antara luas lahan $\left(\mathrm{X}_{1}\right)$, bibit $\left(\mathrm{X}_{2}\right)$, pupuk kandang $\left(\mathrm{X}_{3}\right)$, curahan tenaga kerja $\left(\mathrm{X}_{4}\right)$, umur $\left(\mathrm{X}_{5}\right)$, pendidikan $\left(\mathrm{X}_{6}\right)$, dan jumlah tanggungan keluarga $\left(\mathrm{X}_{7}\right)$ terhadap produksi sawi disajikan pada Tabel 3.

Tabel 3. Hasil Analisis Parsial (Secara Masing-Masing) Luas Lahan ( $\left.\mathrm{X}_{1}\right)$, Bibit $\left(\mathrm{X}_{2}\right)$, Pupuk Kandang $\left(\mathrm{X}_{3}\right)$, Curahan Tenaga Kerja $\left(\mathrm{X}_{4}\right)$, Umur $\left(\mathrm{X}_{5}\right)$, Pendidikan $\left(\mathrm{X}_{6}\right)$, Jumlah Tanggungan Keluarga $\left(\mathrm{X}_{7}\right)$ Berpengaruh Terhadap Produksi Sayuran Sawi

\begin{tabular}{|c|c|c|c|c|c|c|c|}
\hline & \multirow[t]{2}{*}{ Model } & \multicolumn{2}{|c|}{$\begin{array}{c}\text { Unstandardized } \\
\text { Coefficients }\end{array}$} & \multirow{2}{*}{$\begin{array}{c}\text { Standardized } \\
\text { Coefficients } \\
\text { Beta }\end{array}$} & \multirow[t]{2}{*}{$t_{\text {hit. }}$. } & \multirow[t]{2}{*}{ Sig. } & \multirow[t]{2}{*}{$t_{\text {tabel }}$} \\
\hline & & B & Std. Error & & & & \\
\hline \multirow[t]{8}{*}{1} & (Constant) & 126,85 & 81,92 & & 1,55 & 0,15 & \multirow{8}{*}{1,72} \\
\hline & $X_{1}$ & 1052,60 & 82,19 & 0,83 & 12,81 & 0,00 & \\
\hline & $\mathrm{X}_{2}$ & $-6,89$ & 3,35 & $-0,07$ & $-2,05$ & 0,06 & \\
\hline & $\mathrm{X}_{3}$ & 1,48 & 0,52 & 0,19 & 2,79 & 0,01 & \\
\hline & $\mathrm{X}_{4}$ & 2,97 & 8,46 & 0,15 & 0,35 & 0,73 & \\
\hline & $X_{5}$ & 0,10 & 0,93 & 0,00 & 0,11 & 0,91 & \\
\hline & $\mathrm{X}_{6}$ & $-2,09$ & 4,48 & $-0,00$ & $-0,47$ & 0,64 & \\
\hline & $\mathrm{X}_{7}$ & 10,07 & 3,18 & 0,06 & 3,17 & 0,00 & \\
\hline
\end{tabular}

Sumber: data primer (diolah) 2016

Berdasarkan Tabel 3. menunjukkan bahwa nilai koefisien atau paramete regresi linier berganda a sebesar 126,85, $b_{1}$ sebesar 1052,60 $b_{2}$ sebesar - 6,89, b sebesar $1,48, b_{4}$ sebesar $2,97, b_{5}$ sebesar $0,10, b_{6}$ sebesar $-2,09$, dan $b_{7}$ sebesar 10,07, sehingga persamaan regresi yang diperoleh adalah $\mathrm{Yi}=126,85+$ $1052,60 X_{1}-6,89 X_{2}+1,48 X_{3}+2,97 X_{4}+0,10 X_{5}-2,09 X_{6}+10,07 X_{7}$. Hasil analisis pada Tabel 4. dan persamaan regresi yang diperoleh, menunjukkan bahwa faktor produksi yang mempengaruhi produksi sayuran sawi adalah:

$\circ \quad$ Luas lahan $\left(\mathrm{X}_{1}\right)$

Luas lahan berpengaruh nyata terhadap produksi sayuran sawi pada tingkat kepercayaan $90 \% \alpha=10 \%$, dimana probabilitasnya sebesar $0,000<0,1$ atau $t_{\text {hitung }}$ $12,81>\mathrm{t}_{\text {tabel }} 1,72$. Bahkan jika dilihat dari koefisien bertanda positif, yang artinya apabila luas lahan bertambah $100 \%$ akan meningkatkan Produksi sayuran sawi sebesar $1052,60 \%$. Dapat saya asumsikan bahwa hasil penelitian sesuai dengan teori menurut Mubyarto (1989), yaitu lahan sebagai salah satu faktor produks yang merupakan pabriknya hasil pertanian yang mempunyai kontribusi yang cukup besar terhadap usahatani. Besar kecilnya produksi dari usahatani antara lain dipengaruhi oleh luas sempitnya lahan yang digunakan.

- Bibit $\left(\mathrm{X}_{2}\right)$

Bibit berpengaruh sangat nyata pada produksi sayuran sawi dengan tara kepercayaan sebesar $90 \% \alpha=1 \%$, dimana probabilitas $0,06<0,1$ atau $t_{\text {hitung }} 2,05$ $>\mathrm{t}_{\text {tabel }} 1,72$. Sedangkan koefisiennya bertanda negatif yang artinya apabila bibit sawi bertambah $100 \%$, maka produksi sayuran sawi akan menurun sebesar 6,89\%. Jika mengacu pada Haryanto (1995), untuk luasan lahan 1 hektar diperlukan benih sebanyak $750 \mathrm{gr}(0,750-0,85 \mathrm{~kg} / \mathrm{Ha})$ atau 7,5 g/are, berarti untuk rata-rata luasan 0,66 are diperlukan benih sekitar 4,95 gr. Dalam pengamatan di lapangan didapat penggunaan benih untuk luasan 0,66 are adalah sebesar 24 gr, atau lebih banyak 19,05 gr dari yang seharusnya.

- Pupuk kandang $\left(\mathrm{X}_{3}\right)$

Pupuk kandang berpengaruh sangat nyata terhadap produksi sayuran sawi pada tingkat kepercayaan $90 \% \alpha=10 \%$, dimana probabilitasnya sebesar $0.01<$ $\alpha=0,1$ atau $t_{\text {hitung }} 2,79>t_{\text {tabel }} 1,72$. Sedangkan koefisiennya bertanda positif yang artinya apabila pupuk bertambah $100 \%$ maka akan meningkatkan produksi sayuran sawi sebesar $1,48 \%$. Asumsi bahwa penggunaan pupuk kandang merupakan salah satu cara untuk meningkatkan kualitas maupun kuantitas produk sayuran sawi yang dapat diperoleh. Dengan menggunakan pupuk kandang yang efektif dan efisien, maka kualitas tanah sebagai media tanam sawi akan memberikan zat-zat yang dibutuhkan oleh tanaman untuk menghasilkan produksi sawi optimal

- Curahan tenaga Kerja $\left(\mathrm{X}_{4}\right)$

Curahan tenaga kerja tidak berpengaruh nyata pada produksi sayuran sawi dengan taraf kepercayaan sebesar $90 \% \alpha=10 \%$, dimana probabilitas $0,73>0,1$ atau $t_{\text {hitung }} 0,35<t_{\text {tabel }} 1,72$. Berdasarkan nilai koefisien bertanda positif yang artinya apabila curahan tenaga kerja petani responden usahatani sayuran sawi bertambah $100 \%$, maka produksi sayuran sawi akan meningkat sebesar $2,97 \%$. Tenaga kerja merupakan tulang punggung dalam kegiatan usahatani sayuran sawi dengan demikian saya menduga bahwa tenaga kerja di daerah penelitian memiliki manajemen yang kurang baik dalam pengelolaan usahataninya.

○ $\operatorname{Umur}\left(\mathrm{X}_{5}\right)$

Umur tidak berpengaruh nyata pada produksi sayuran sawi dengan taraf kepercayaan sebesar $90 \%$ dengan $\alpha=10 \%$, dimana probabilitas $0,91>0,1$ atau $\mathrm{t}_{\text {hitung }} 0,11<\mathrm{t}_{\text {tabel }} 1,72$. Berdasarkan nilai koefisien bertanda positif yang artinya apabila umur Petani responden usahatani sayuran sawi bertambah $100 \%$, maka produksi sayuran sawi akan meningkat sebesar $0,10 \%$.

○ Pendidikan $\left(\mathrm{X}_{6}\right)$

Pendidikan tidak berpengaruh nyata pada produksi sayuran sawi dengan taraf kepercayaan sebesar $90 \%$ dengan $\alpha=1 \%$, dimana probabilitas $0,65>0,1$ atau $t_{\text {hitung }} 0,46<t_{\text {tabel }} 1,72$. Sedangkan nila koefisiennya bertanda negatif yang artinya apabila pendidikan responden bertambah $100 \%$, maka produksi sayuran sawi akan menurun sebesar 2,09\%. Mosher (1985), menyatakan bahwa pendidikan menentukan kemampuan petani dalam mengambil keputusan yang dilaksanakan pada usahataninya. Sehingga tingkat pendidikan petani yang rendah menyebabkan sulit dalam mengelola dan memanfaatkan sumber daya alam, tenaga kerja, dan modal secara optimal. Dapat diasumsikan bahwa hasil penelitian menunjukkan pendidikan tidak berpengaruh karena tingkat pendidikan di lokasi penelitian masih sangat rendah yakni $15 \%$ tidak tamat SD, dan $80 \%$ adalah SD.

○ Jumlah tanggungan keluarga $\left(\mathrm{X}_{7}\right)$

Jumlah tanggungan keluarga berpengaruh sangat nyata terhadap produksi sayuran sawi pada tingkat kepercayaan $90 \%$ dengan $\alpha=10 \%$, dimana probabilitasnya sebesar $0.00<0,1$ atau $\mathrm{t}_{\text {hitung }} 3,16>\mathrm{t}_{\text {tabel }} 1,72$. Bahkan jika dilihat dari koefisien bertanda positif, yang artinya apabila jumlah tanggungan keluarga bertambah $100 \%$ akan meningkatkan produksi sayuran sawi sebesar $10,07 \%$ Mosher (1985), berpendapat bahwa keluarga merupakan salah satu faktor yang mempengaruhi petani dalam pengambilan keputusan untuk pengelolaan usahataninya. Kasih sayang terhadap keluarga dan beban tanggungan yang dimiliki menimbulkan keinginan dan motivasi suami dalam hal ini petani responden untuk dapat menikmati taraf hidup yang lebih baik agar keluarganya hidup lebih bahagia.

\section{Simpulan}

Usahatani sayuran sawi terdiri dari: 1) pengolahan lahan, sistem pengolahan lahan dilakukan dengan cara tanah dibalik menggunakan linggis. Setelah tanah dibalik langsung pembuatan bedeng dengan ukuran panjang 10 meter, 12 meter, dan 15 meter, lebar 1 meter, tinggi bedeng $20 \mathrm{~cm}$, jarak antar bedeng $20 \mathrm{~cm}$ sedangkan jarak antar blok $50 \mathrm{~cm}$, kemudian diberi dasar dengan; 2) Persemaian yang dilakukan yakni lahan yang sudah disediakan untuk persemaian di sirami air terlebih dahulu kemudian ditaburi benih sayur manis dan ditutupi lagi dengan tanah sehingga taburan bibit sawi tertutup dan tidak dimakan burung atau ayam; 3) Penanaman dilakukan setelah bibit sayur manis mempunyai daun 3-4 helai daun, sebelum menanam bedengan harus di sirami air, baru ditanami dengan jarak tanam $\pm 5 \mathrm{~cm} \times 5 \mathrm{~cm}$ atau $1 / 2$ jengkal; 4) Pemeliharaan terdiri dari penyiraman dan penyiangan; dan 6) Panen dan pasca panen, petani melakukan panen setelah sayur sawi berumur 21 hari, saat panen petani terlebih dahulu melihat warnanya, bentuk, dan ukurannya. Sayur manis dicabut bersama akarnya kemudian disuci dengan air, lalu dipotong akarnya baru diikat sesuai kebutuhan atau harga yang sudah ditentukan. Berdasarkan uji $\mathrm{F}$, secara bersama-sama luas lahan $\left(\mathrm{X}_{1}\right)$, bibit $\left(\mathrm{X}_{2}\right)$, pupuk kandang $\left(\mathrm{X}_{3}\right)$, curahan tenaga kerja $\left(\mathrm{X}_{4}\right)$, umur $\left(\mathrm{X}_{5}\right)$, pendidikan $\left(\mathrm{X}_{6}\right)$, dan jumlah tanggungan keluarga $\left(\mathrm{X}_{7}\right)$ berpengaruh nyata terhadap produksi sawi $(\hat{\mathrm{Y}} 1)$. Sedangkan berdasarkan uji $\mathrm{t}$, secara parsial variabel luas lahan $\left(\mathrm{X}_{1}\right)$, bibit $\left(\mathrm{X}_{2}\right)$, pupuk kandang $\left(\mathrm{X}_{3}\right)$ dan jumlah tanggungan keluarga $\left(\mathrm{X}_{7}\right)$ berpengaruh nyata terhadap produksi sawi, sedangkan variabel curahan tenaga kerja $\left(\mathrm{X}_{4}\right)$, umur $\left(\mathrm{X}_{5}\right)$, dan pendidikan $\left(\mathrm{X}_{6}\right)$, tidak berpengaruh nyata terhadap produksi sawi. 
Pustaka

Darmawaty, S., 2005. Beberapa Faktor Sosial Ekonomi yang Mempengaruhi Produktivitas, Biaya Produksi dan Pendapatan Usahatani Semangka di Kabupaten Serdang Bedagai. Medan: Departemen Sosial Ekonomi Pertanian Universitas Sumatera Utara.

Haryanto, Eko, Tina Suhartini, Estu Rahayu, dan Hendro Sunarjono. 1995. Sawi dan. Salada. Jakarta: Penebar Swadaya.

Mosher. 1985. Menggerakkan dan Membangun Pertanian. Jakarta: CV Jasaguna Mubyarto. 1989. Pengantar Ekonomi Pertanian. Jakarta: LP3ES.

Nubatonis, A. 2016. Analisis Pendapatan Usahatani Sawi di Desa Humusu Oekolo Kecamatan Insana Utara Kabupaten Timor Tengah Utara. AGRIMOR, 1(01): 1-2.

Sudjana. 1992. Metode Statistika. Edisi kelima. Bandung: Tarsito. 